\title{
Imaging techniques in cardiac resynchronization therapy
}

\author{
Maria Isabel Sá · Albert de Roos · Jos J. M. Westenberg • \\ Lucia J. M. Kroft
}

Received: 8 February 2007 / Accepted: 19 April 2007/Published online: 15 May 2007

(C) Springer Science+Business Media B.V. 2007

\begin{abstract}
Cardiac resynchronization therapy is a high cost therapeutic option with proven efficacy on improving symptoms of ventricular failure and for reducing both hospitalization and mortality. However, a significant number of patients do not respond to cardiac resynchronization therapy that is due to various reasons. Identification of the optimal pacing site is crucial to obtain the best therapeutic result that necessitates careful patient selection. Currently, using echocardiography for mechanical dyssynchrony assessment performs patient selection. Multi-Detector-Row Computed Tomography (MDCT) and Magnetic Resonance Imaging (MRI) are new imaging techniques that may assist the cardiologist in patient selection. These new imaging techniques have the potential to improve the success rate of cardiac resynchronization therapy, due to pre-interventional evaluation of the venous coronary anatomy, to evaluation of the presence of scar tissue, and to improved evaluation of mechanical dyssynchrony. In conclusion, clinical issues associated with heart failure in potential candidates for cardiac resynchronization therapy, and the information regarding this
\end{abstract}

M. I. Sá · A. de Roos · J. J. M. Westenberg .

L. J. M. Kroft $(\bowtie)$

Department of Radiology, C2-S, Leiden University

Medical Center, Albinusdreef 2, 2333 ZA Leiden,

The Netherlands

e-mail: 1.j.m.kroft@lumc.nl therapy that can be provided by the imaging techniques echocardiography, MDCT, and MRI, are reviewed.

Key words Cardiac imaging - Computed tomography · Magnetic resonance imaging · Resynchronization

\section{Introduction}

Cardiac resynchronization therapy (CRT), obtained by implanting a biventricular pacemaker, is an established therapeutic option for patients with reduced left ventricular ejection fraction $(\leq 35 \%)$, prolonged QRS interval ( $\geq 120 \mathrm{~ms})$ and NYHA class III/IV systolic heart failure (HF) despite optimal medical therapy. CRT improves symptoms and decreases both hospitalizations and mortality [1]. CRT is effective by reversing left ventricular (LV) remodelling and increasing the ejection fraction (EF), while correcting the main cause of LV functional and morphologic disturbances, named mechanical dyssynchrony, which is basically an activation delay between cardiac chambers or LV segments. LV reverse remodelling, defined by a reduction in end-systolic and end-diastolic diameters and volumes has been referred as an indicator to CRT response. However, between $20 \%$ and $30 \%$ of patients do not respond to CRT [2]. Suggested reasons include a prolonged QRS duration without 
mechanical dyssynchrony, and therapeutic failure due to mismatch between the LV lead position and the most delayed myocardial region [2-4]. It has been suggested that measuring mechanical dyssynchrony by echocardiography may better identify patients who are likely to respond to CRT [5]. Currently echocardiography has been used in selection and follow-up of candidates to CRT, namely in the evaluation of LVEF and LV remodelling and ventricular dyssynchrony. Multi-Detector-Row Computed Tomography (MDCT) and Magnetic Resonance Imaging (MRI) are increasingly used for cardiac evaluation. MDCT and MRI allow depiction of cardiac anatomy with high spatial resolution as well as highly accurate measurements of cardiac function [6-8]. In this review clinical issues concerning CRT as well as clinical applications of these three imaging modalities will be discussed.

\section{Clinical issues}

Left ventricular systolic dysfunction and remodelling

Heart Failure (HF) and cardiomyopathy refer to a spectrum of diseases that encompass various clinical entities, where inadequate function of one or both ventricles forms the basis of cardiac disease. Chronic HF develops after injury or stress to the myocardium, due to a variety of causes, e.g. ischemia, hypertension, valvular disease, myocarditis, etc. In compensatory response the heart remodels, leading to changes in myocardial structure and neurohormonal milieu of the entire cardiovascular system. Increased wall stress leads to alterations in the geometry of the heart, with hypertrophy or dilatation of the ventricle(s) [9]. Increased LV size and decreased LVEF are associated with increased neurohormonal activation and predict prognosis. Also when class III or IV symptoms and LVEF less than 30\% are present, LV dimension is considered a strong predictor of mortality [10]. Moreover, right ventricular (RV) dysfunction is also associated with increased mortality [11].

The effects of CRT can be divided into early and long-term effects. Studies in the acute setting have demonstrated that CRT abruptly increases LVEF with improved energetic chamber efficiency [12-15]. The main long-term CRT effect is the so-called " $\mathrm{LV}$ reverse remodelling", $[2,5]$. A $10 \%$ reduction in $\mathrm{LV}$ end-systolic and end-diastolic volumes has been associated with increased LVEF [16]. Even this relatively small amount of LV reverse remodelling has been shown to be a strong predictor for improved survival and decrease of HF events [2, 15-17].

Diastolic dysfunction

Most HF are associated with an impaired LVEF below $50 \%$ which is usually accompanied by diastolic dysfunction [1]. However, 30-50\% of $\mathrm{HF}$ patients have LVEF of $50 \%$ or greater. These patients are assumed to have diastolic dysfunction as the primary mechanism of heart failure; however, diastolic dysfunction is variably identified and diagnosed [18]. The combined assessment of LV inflow, pulmonary venous filling pattern and the mitral annulus or basal ventricular myocardial velocities allows identifying three characteristic abnormal diastolic ventricular filling patterns: "impaired relaxation" "pseudonormalized filling', and "restrictive filling" (Table 1) that represent increasing degrees of diastolic dysfunction, respectively [1, 18-21]. The impact of CRT on diastolic function is not fully understood [22]. Nevertheless, it has been shown that 12 months after CRT, reverse remodelling was accompanied by improvements of LV diastolic function [23].

Mitral regurgitation

End-stage HF usually gives rise to mitral regurgitation (MR) and the resulting LV volume overload further deteriorates $\mathrm{LV}$ function, which in turn increases MR [24]. Causes of MR include: (1) Incomplete closure of the mitral valve leaflets due to systolic retraction of the papillary muscles towards the apex in the dilated LV [25]; (2) Papillary muscle dysfunction due to wall motion abnormalities in the inferior/posterior regions [26]; (3) LV dyssynchrony [27] and (4) Incomplete mitral valve closure due to prolonged AV interval with delayed LV contraction that results in pre-systolic (diastolic) MR [28].

The severity of MR depends on LV dimensions and correlates with outcome [29]. Significant reduction in MR has been reported immediately as well as late after CRT [17, 30, 31]. The immediate reduction 
Table 1 Abnormal diastolic ventricular filling patterns

\begin{tabular}{llllll}
\hline & $\begin{array}{l}\text { Deceleration time } \\
\text { of E velocity (ms) }\end{array}$ & $\begin{array}{l}\text { Isovolumetric } \\
\text { relaxation time }(\mathrm{ms})\end{array}$ & $\begin{array}{l}\mathrm{E} \\
\text { velocity }\end{array}$ & $\begin{array}{l}\mathrm{A} \\
\text { velocity }\end{array}$ & $\begin{array}{l}\text { E/A } \\
\text { ratio }\end{array}$ \\
\hline $\begin{array}{l}\text { Impaired relaxation } \\
\text { Pseudonormalization }\end{array}$ & $>240$ & $>110$ & $\downarrow$ & $\uparrow$ & $<1.0$ \\
$\quad 160-240$ & $<90$ & $\uparrow$ & $\downarrow$ & $1.0-$ \\
filling & $<160$ & $<70$ & $\uparrow$ & $\downarrow$ & $>1.5$ \\
Restrictive filling & $<$ & & & $\downarrow$ & $\uparrow$ \\
\hline
\end{tabular}

in MR severity has been attributed to elimination of the pre-systolic MR component by pacing with a short (optimized) AV delay, and by improved coordination of ventricular contraction, that included resynchronized papillary muscle activation [16]. Late reduction in MR has been observed months after CRT and is probably related to LV reverse remodelling [17].

Left ventricular electrical and mechanical dyssynchrony

The QRS complex represents the vectorial sum of electrical forces generated by myocardial masses over time. Normal electrical activation propagates as a uniform high-velocity wavefront through the myocardial Purkinje network. In damaged myocardium, altered conduction properties impair the velocity and direction of electrical propagation [32]. Abnormal ventricular depolarization, manifesting as QRS interval prolongation $\geq 120 \mathrm{~ms}$, also known as bundle branch block, generates regions of both early and delayed ventricular contraction. The delayed segments accommodate contractile forces and volume, hereby reducing LV systolic function.

Increasing QRS interval duration is directly related to impaired LVEF [33-35].

The prevalence of bundle branch block is about $20 \%$ in the general HF population $[33,34]$ and up to $35 \%$ among patients with more severely impaired systolic function. QRS morphology and duration depends on myocardial mass, but provide no information concerning regional mechanical changes. In failing myocardium, heterogeneous interstitial fibrosis results in disorganized depolarization that causes abnormal regional loading conditions, inducing further localized fibrosis and hypertrophy with consequent mechanical dyssynchrony [36].

Although coupling of electrical activation and mechanical contraction is not completely defined, there is convincing evidence of electromechanical dissociation [32]. In myocardial ischemia, impaired regional contractility and wall motion abnormalities frequently produce mechanical dyssynchrony without disturbing electrical conduction [32]. After electrical activation, regional mechanical delays in time to peak systolic velocity $\left(T_{\mathrm{s}}\right)$ occurs in addition to delays in isovolumetric contraction [37]. Despite correlation between QRS narrowing and CRT response [38-41], haemodynamic studies indicate CTR benefits relate to improvements in mechanical rather than electrical coordination [42-45].

Mechanical dyssynchrony may be considered in terms of inter- and intraventricular components. Interventricular dyssynchrony refers to delayed activation of the $\mathrm{LV}$ relative to the $\mathrm{RV}$. Intraventricular dyssynchrony refers to delayed activation of one $\mathrm{LV}$ region relative to another. Because of ventricular interdependence, correction of intraventricular dyssynchrony frequently results in improvement of interventricular dyssynchronization as well. QRS interval duration alone has no correlation with intraventricular dyssynchrony and only has a limited relationship with interventricular dyssynchrony and consistently fails to predict response to CRT [32].

Ischemic heart disease

In the United States, ischemic heart disease accounts for $50-70 \%$ of HF. In patients who are potential candidates for $\mathrm{CRT}$, coronary artery risk stratification is often necessary to exclude myocardial revascularization as therapeutic option. Ischemia worsens the prognosis and this may be due to a higher incidence of diabetes in the ischemic population [46]. It has been demonstrated that one year after CRT, patients with ischemic HF had less LV remodelling and symptomatic improve than patients with non-ischemic heart failure [23]. In addition, patients with ischemic HF have higher risk of sudden death. Moreover, in patients who have a past history of myocardial infarction, scarred tissue may complicate 
LV dyssynchrony evaluation. It is currently unclear whether LV pacing in a scarred region will be beneficial [5].

\section{Coronary venous system}

The cardiac venous system is currently gaining interest. Two-dimensional (2D) transthoracic echocardiography (TTE) allows visualization of the coronary sinus, the gateway to LV transvenous lead placement to achieve biventricular pacing. Although the success rate for transvenous LV lead placement is relatively high (88-95\% in large clinical trials), the procedure is not successful in 5-12\% of patients [47]. Failure of LV lead placement has been attributed to the inability to insert catheters in the coronary sinus but also to the lack of suitable side branches [47, 48].

The coronary venous anatomy can be systematically evaluated in a form comparable to that established by echocardiography and LV angiography for the coronary artery system [49], adding information concerning the course and dimensions of the coronary veins and tributaries. It facilitates optimal LV lead placement by identifying the vein or tributary that corresponds to the site of latest LV myocardial activation, the optimal pacing site for successful CRT [50]. However, the most optimal CRT pacing site may not always have a suitable vein. In particular, identifying patients without suitable coronary veins for pacemaker lead implantation is important as these patients may be best treated by epicardial pacemaker lead implantation that requires a minimal surgical approach [48].

\section{Echocardiography}

General considerations

Echocardiography has been used in selection of patients for CRT and their follow-up, namely in the evaluation of LVEF, LV remodelling and mechanical dyssynchrony. Although echocardiography has a well-recognized value in general cardiac assessment and is a widely available, non-invasive imaging modality, the technique has certain limitations: (1) It is a $2 \mathrm{D}$ technique where measures are obtained using various views and geometrical models that may provide sources of error; (2) The time needed to perform extensive measurements may limit application in routine clinical practice and (3) Reproducibility of acquired data may be limited by hemodynamic variations, operator experience, machine settings, available acoustic window, and angle of incidence effects.

Echocardiography of left ventricular systolic function

2D-TTE is used for qualitative and semi-quantitative $\mathrm{LV}$ function evaluation. Global function is assessed, measuring the degree of endocardial motion and ventricular wall thickening for various cardiac segments and by integrating the information from several tomographic planes. For evaluation of regional function, the $\mathrm{LV}$ is divided into 17 segments and regional wall motion is scored according to the recommendations of American Society of Echocardiography (ASE) [51]. The accuracy of qualitatively estimating EF largely depends on the experience of the reader (an experienced reader estimates LVEF in intervals of 5-10\%), and also depends on the acoustic window that renders up to $10 \%$ of the endocardial borders inadequate. Quantitative assessment involves geometrical assumptions and formulas. The most often used is the modified Simpsońs rule to calculate LVEF. EF is calculated as EF $=100 \times(\mathrm{EDV}-\mathrm{ESV}) /$ $\mathrm{EDV}$, where EDV and ESV are the end-diastolic and end-systolic volumes, respectively, obtained from endocardial border detection in four-chamber view and two-chamber view at end-diastole and endsystole [52]. This method has some limitations that include the possibility of incorrect endocardial border detection, and LVEF calculations that cannot be corrected for mitral or aortic regurgitation.

Echocardiography of diastolic function

LV inflow parameters assessed by pulsed wave Doppler are well established and measure early (E) and atrial (A) filling wave velocities, E/A ratio, deceleration time of early filling, and isovolumetric relaxation time [21]. The pulmonary venous inflow pattern into the left atrium is helpful in distinguishing between normal and pseudonormal mitral inflow patterns, according to the predominance of systolic velocity (S wave) or diastolic velocity (D wave), respectively [21]. 
Tissue Doppler Imaging (TDI) measures the motion of the mitral annulus or basal LV myocardial velocities by fixing the sample in these sites. In healthy persons the mitral annulus motion is almost a mirror image of the transmitral inflow pattern [19]. Mitral annulus or basal LV myocardial systolic (Sm), early diastolic (Em) and late diastolic (Am) velocities correlate well with standard mitral and pulmonary vein inflow patterns of diastolic function.

\section{Echocardiography of mitral regurgitation}

2D Doppler TTE and transesophageal echocardiography (TEE) allow accurate determination of the cause and severity of MR. MR severity assessment is a very complex measure that takes into account a set of parameters such as regurgitant volume and fraction, colour Doppler regurgitant jet area and jet/left atrial area ratio, vena contracta width measurement (narrowest portion of the jet) and proximal isovelocity surface area (PISA) measurement. In ideal conditions, colour Doppler jet area and jet/left atrial area ratio used for assessing the severity of MR have high sensitivity and specificity as compared with conventional angiography; vena contracta measurements correlate well with regurgitant volume and regurgitant orifice area, and a high correlation exists between the regurgitant volume as assessed by the PISA method and angiography [53]. Additional indirect clues like pulmonary venous and LV inflow patterns, and left atrial size provide supplementary information regarding severity of MR. TEE, when compared to TTE, is less limited by chest structures attenuation, but TEE is semi-invasive.

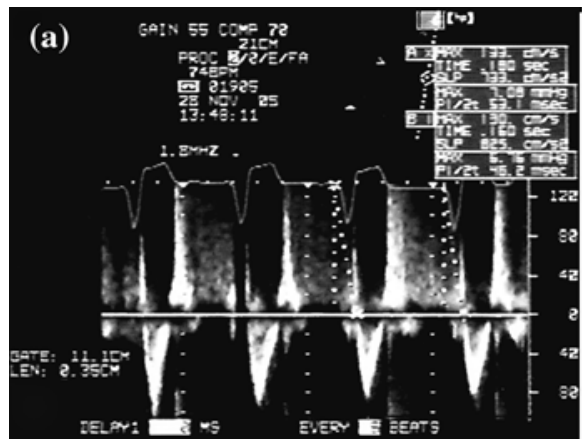

Fig. 1 Two-dimensional echocardiographic image of a sixty three years old male, candidate to cardiac resynchronization therapy, presenting interventricular dyssynchrony shown by
Echocardiography of left ventricular mechanical dyssynchrony

Mechanical dyssynchrony can be assessed using Mmode and conventional pulsed Doppler TTE, TDI, strain rate imaging (SRI), and tissue synchronization imaging (TSI). Strain can be defined as change in the length per unit length much like relative shortening.

Interventricular dyssynchrony or " Interventricular mechanical delay" (IVMD) (Fig. 1) is the difference between the left and right ventricular pre-ejection time intervals, measured from the onset of the QRS complex to the beginning of aortic and pulmonary Doppler flow velocity curves [54]. An IVMD of $40 \mathrm{~ms}$ or more represents interventricular dyssynchrony [55-57]. The predictive value of IVDM is weak, as multiple factors influence ventricular ejection, including changes in preload and afterload. In particular, prolonged RV pre-ejection time interval in pulmonary hypertension and RV dysfunction reduce the IVDM accuracy [56].

Intraventricular dyssynchrony has been defined by three conventional parameters: (1) LV pre-ejection time interval delays larger than or equal to $140 \mathrm{~ms}$ [54, 57, 58]; (2) Post-systolic contraction or delayed activation of the lateral wall (co-existence of systole and diastole) (Fig. 2) measured by overlap of the LV lateral wall contraction (by using M-mode) and onset of diastolic filling (by using transmitral Doppler Ewave onset), that strongly suggests severe intraventricular dyssynchrony [37] and (3) Septal-to-posterior wall motion delay (Fig. 3) that measures the time between maximal displacement of the septum and posterior wall on M-mode, with a delay that is larger

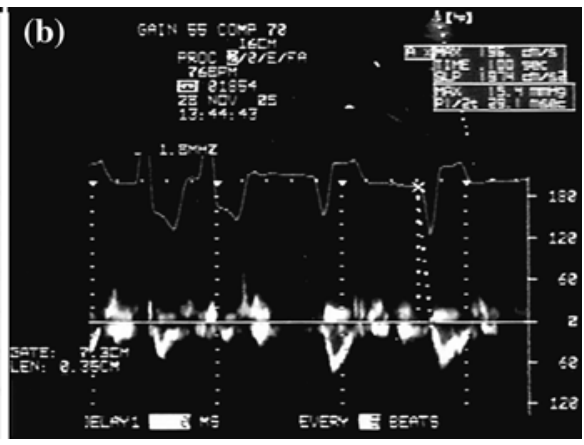

interventricular mechanical delay with a difference between the (a) aortic pre-ejection time and (b) pulmonar pre-ejection time, which was $>40 \mathrm{~ms}$ 


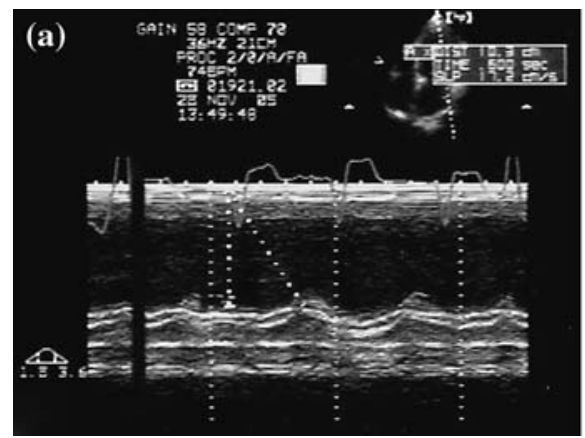

Fig. 2 Echocardiographic image of a sixty eight years old female, candidate to cardiac resynchronization therapy, showing a post-systolic contraction or delayed activation of lateral wall (co-existence of systole and diastole), measured by

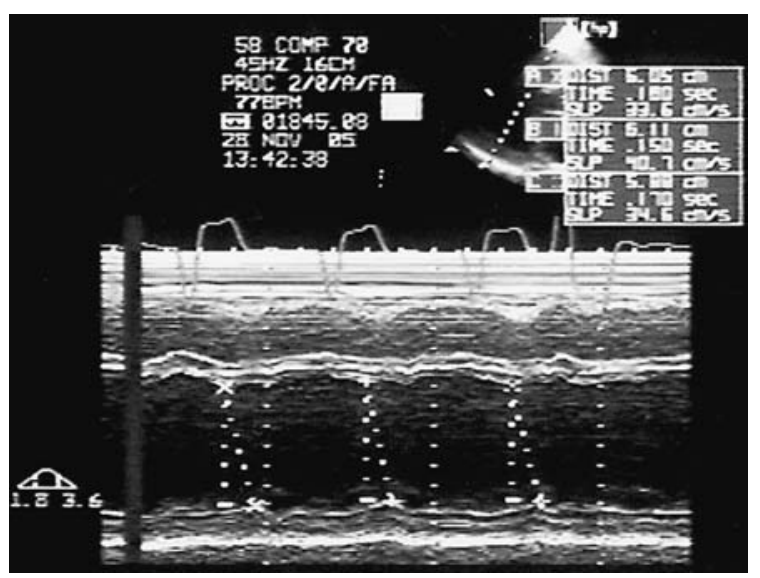

Fig. 3 M-mode echocardiographic image of a fifty three years old female, candidate to cardiac resynchronization therapy, showing septal-to-posterior wall motion delay (>140 ms).

than $130 \mathrm{~ms}[39,59,60]$. However, several geometrical and pathophysiological limitations exist that may render these echocardiographic measures inaccurate [60].

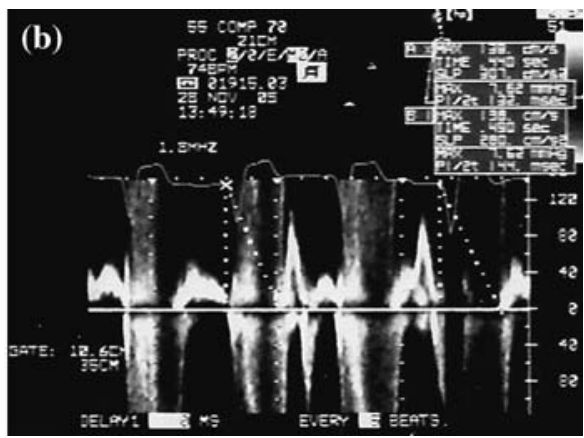

overlap of the LV lateral wall contraction (by using M-mode) and onset of diastolic filling (by using transmitral Doppler E-wave onset)

Intraventricular electromechanical delay is evaluated by longitudinal segmental myocardial contraction at TDI from apical 4, 3, and 2 chamber views. Either time-to-peak systolic velocity or time-to-onset of systolic velocity are measured relative to the beginning of the QRS complex. Intraventricular LV dyssynchrony is quantified either by the standard deviation of 12 segments $\left(T_{\mathrm{s}}\right.$-SD-12 or dyssynchrony index) or the maximal temporal difference between two $\left(T_{\mathrm{s}}-2\right.$, EMD-2) or more LV segments (e.g. $T_{\mathrm{s}}-6$, $T_{\mathrm{s}}-12$ ). Larger values of any parameter indicate more severe dyssynchrony [32]. A mechanical delay between the septum and the lateral wall of $65 \mathrm{~ms}$ on tissue TDI (Fig. 4) has been found as cut-off value predictor for response to CRT [54].

The tissue synchronization imaging software automatically measures the time-to-peak systolic velocity, colour codes delays and then superimposes colour mapping on real-time 2D images. Colour-coded display of myocardial displacement allows immediate visual identification of regional delay that ranges from green (normal) to red (severe delay) and permits
Fig. 4 Tissue Doppler Image echocardiography of 74-years-old male, candidate to cardiac resynchronization therapy, showing mechanical delay between (a) the interventricular septum and (b) the lateral left ventricular wall, that was $>65 \mathrm{~ms}$
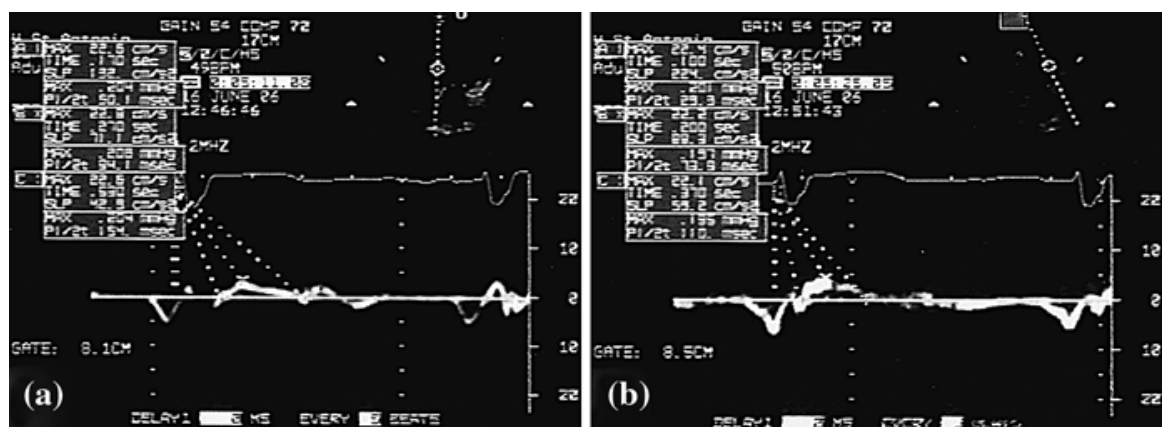
fast calculation of dyssynchrony parameters [32]. TDI has similar limitations as conventional Doppler imaging. Notably, the angle between the incident ultrasound beam and vector of myocardial motion influences measurements, and excessive gain causes spectral broadening and velocity overestimation [32]. Strain rate imaging by speckle tracking can overcome several limitations of TDI by measuring localized myocardial deformation that distinguishes passive and active systolic contraction, although the reproducibility of this technique remains limited [61-64].

The primary objective of CRT is to restore the normal ventricular activation pattern. Several studies have shown that the presence of intraventricular dyssynchrony is a major predictor of response to CRT $[16,40,65]$. It is important to match the pacing site with the area of maximum mechanical delay. Pacing at the site of maximal time-to-peak myocardial velocity in patients with HF and LV dyssynchrony has been associated with good clinical response after CRT. However, delay in peak myocardial velocities in the antero-septal area has been associated with a failure of CRT response. The site of latest activation is predictive for the success of CRT response and individually tailored LV lead positioning should be considered before CRT [66]. Real-time 3D echocardiography allows rapid and accurate evaluation of LV volumes and their changes, having a great potential for assessment of LV dyssynchrony, and allows determining dyssynchrony between all segments [67]. Phase analysis of segmental volume-time curves based on 3D data demonstrates changes of regional myocardial motion and LV contraction pattern in a quantitative way [68]. However, defining and expression the delay remains an important issue that necessitates standardization.

\section{Cardiac CT angiography}

\section{General considerations}

Since the first report concerning non-invasive coronary imaging with electron beam computed tomography angiography published in 1995, cardiac computed tomography techniques have improved rapidly. Nowadays 64-slice multi-detector-row computed tomography (MDCT) systems are available, offering good diagnostic image quality with short acquisition times $[69,70]$. Because a regular rhythm and low heart rate are essential for high-quality images, $\beta$-blockers are usually administered before the examination. MDCT provides information concerning the coronary arteries and veins, LV volumes and function as well as myocardial tissue perfusion, while requiring the use of iodinated contrast agents [6]. Use of iodinated contrast agents is of concern in patients with impaired renal function. Furthermore, MDCT coronary angiography is associated with an effective radiation dose that varies between 8 and $21 \mathrm{mSv}$, with or without prospective tube current modulation [69, 71, 72].

MDCT of left ventricular systolic dysfunction and remodelling

MDCT is a three-dimensional (3D) imaging modality that is used for evaluation of ventricular function with high accuracy and precision [7]. ECG-synchronized MDCT allows fast and (semi)automatic determination of LV systolic global function, with LV parameters such as LV volumes and LVEF with high accuracy [7, 73]. Also, RV systolic function can be accurately assessed by MDCT [74]. MDCT LV regional wall function analysis at rest is feasible [75], although further improvements in temporal resolution are needed to match the results as obtained from cine MRI [8].

\section{MDCT of the coronary arteries}

The majority of potential CRT candidates have suspected or known coronary artery disease, justifying coronary artery evaluation before CRT. As compared to conventional coronary angiography, 64-slice MDCT is an accurate and non-invasive method to detect and quantify obstructive and non-obstructive coronary artery disease [69, 70], (Fig. 5) although the quantification of luminal obstruction is limited due to technical restrictions. On a patient basis it has been found that the sensitivity for identifying patients with stenoses that required angioplasty or bypass surgery was $94 \%$ [75]. MSCT has currently a significantly higher accuracy for detecting or excluding significant coronary artery disease than 1.5 T MRI systems [76]. Experimental and patient studies have shown that with delayed enhancement MDCT techniques, the location and extent of myocardial scar tissue can be accurately 
(a)

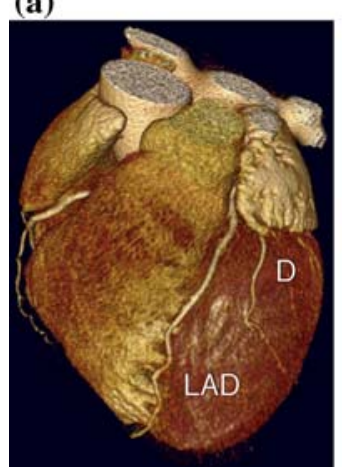

(b)

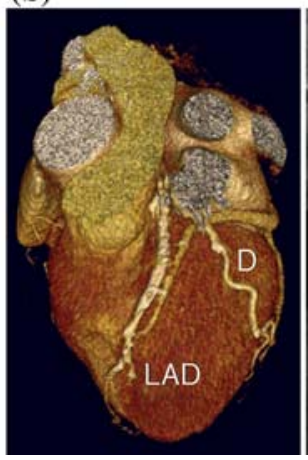

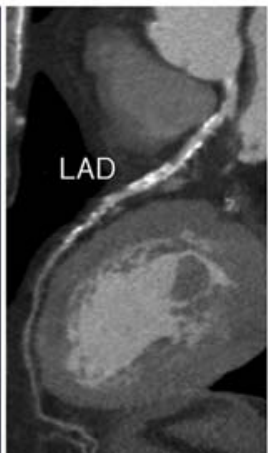

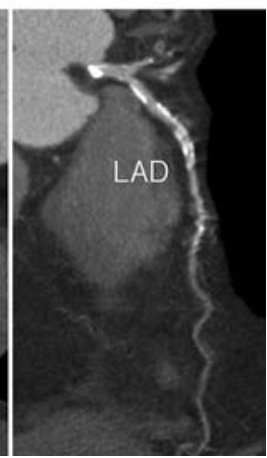

Fig. 5 Multi-detector computed tomography coronary angiography acquired with $0.5 \mathrm{~mm}$ collimation and half-scan reconstruction (Toshiba Aquilion $64 \mathrm{CT}$-scanner) in a 66years-old male patient showing normal coronary arteries (a) and in a sixty six years old male patient showing coronary artery disease (b). The left anterior descending (LAD) coronary

assessed and is comparable to that assessed with MRI $[77,78]$.

\section{MDCT of the coronary veins}

The clinical potential of MDCT to disclose the coronary venous system anatomy (Fig. 6) has been recognized and advocates its applications for CRT candidates [79]. It may help in predicting the technical difficulty, selecting the appropriate equipment, and identifying the venous tributary with appropriate diameter in the region of latest LV artery and a diagonal branch (D) are visualized in both patients. Note the irregular lumen of the LAD that was heavily calcified in the patient with coronary artery disease (b). Curved multiplanar reconstructions of the diseased LAD that displays the artery in a single image is shown in two perpendicular longitudinal directions

activation, where the LV lead should ideally be positioned. It may also identify patients who do not have adequate venous side branches available or patients who have obstruction and ostial narrowing (e.g., by a thebesian valve)-these patients are potential candidates for epicardial lead placement using a minimal invasive surgical approach $[49,80$, 81]. MDCT studies have shown that the posterior vein of the $\mathrm{LV}$ and the left marginal vein were absent in $5 \%$ and $39 \%$ of patients, respectively, and variation in venous drainage patterns largely agrees with the results of anatomic studies [80, 82, 83].
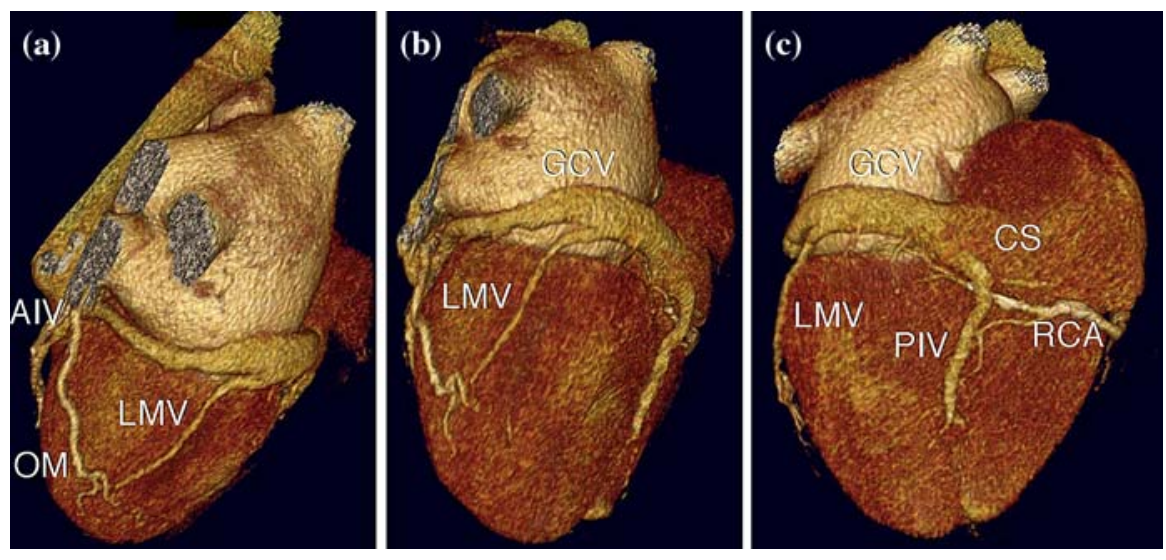

Fig. 6 Multi-detector computed tomography angiography $(0.5 \mathrm{~mm}$ collimation and half-scan reconstruction, sixty six years old male patient). Volume rendering images showing the coronary venous system. $\mathrm{CS}=$ coronary sinus; $\mathrm{GCV}=$ great cardiac vein; AIV = anterior interventricular vein; $\mathrm{LMV}=$ left marginal vein; PIV = posterior interventricular vein; $\mathrm{OM}=$ obtuse marginal coronary artery branch; $\mathrm{RCA}=$ right coronary artery 


\section{Cardiac magnetic resonance imaging}

General considerations

MRI provides accurate morphological and functional analysis irrespective of the patient's anatomy [84]. The technique is non-invasive and most gadoliniumchelate contrast agents are less toxic than iodinated contract agents used for CT. However, MRI is not feasible in all patients; claustrophobia is occasionally a problem, and absolute contraindications include cerebral clips, pacemakers, and defibrillators [85], although some modern pacemakers and defibrillators have shown MRI compatibility in experimental studies [86, 87].

MRI of left ventricular systolic dysfunction remodelling

3D-cine MRI is performed in any volume desirable without geometrical assumptions. The technique has excellent temporal and good spatial resolution, showing high accuracy and reproducibility for quantifying LV volumes and function [7]. Currently, this is achieved using fast gradient-echo sequences (Fig. 7). Thirty to forty cardiac phases are obtained with a time resolution of less than $40 \mathrm{~ms}$ [88].

MRI myocardial tagging (Fig. 8) concerns a method where the myocardium is labelled (tagged) by selective saturation prepulses in specific myocardial regions in planes perpendicular to the imaging plane. The tags appear as a pattern of horizontal and vertical lines, forming a grid superimposed on the image. The analysis of tag deformation enables quantification of global and regional myocardial deformation during the cardiac cycle. The tagging technique is most applied in ischemic heart disease [89].

MRI of diastolic dysfunction

Cardiac MRI is emerging as a powerful and noninvasive technique with the unique potential of $3 \mathrm{D}$ analysis of diastolic function [90]. Phase-contrast or velocity encoded MRI permit quantification of flow across the mitral valve, providing $\mathrm{E}$ and $\mathrm{A}$ peak velocities and volume [91-93] and identification of the pulmonary venous $\mathrm{S}$ wave, $\mathrm{D}$ wave and atrial reversal wave components, in close agreement with that of Doppler echocardiography [91]. 2D echocardiography methods may limit obtaining correct flow velocity profiles $[94,95]$. This is not the case with $3 \mathrm{D}$ MRI techniques.

Analogous to flow velocities, velocity encoded MRI allows measurement of tissue velocities. In each myocardial voxel, the strain rate can be quantified [96]. Tissue MRI is a feasible method to assess septal tissue velocities (Ea). The combination of $\mathrm{E}$ and $\mathrm{Ea}$ allows the estimation of filling pressure, comparable to Doppler echocardiography. MRI measurements have shown good agreement with invasive measurements [97].

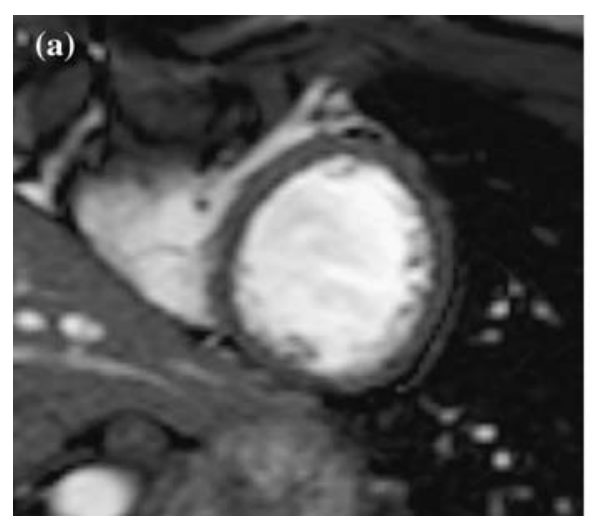

Fig. 7 Magnetic resonance imaging in a 20-year-old healthy male. Short-axis images at left midventricular level. Functional imaging (balanced turbo field-echo sequence with TR $3.8 \mathrm{~ms}$, TE $1.9 \mathrm{~ms}$, flip angle $70^{\circ}$, slice thickness $8 \mathrm{~mm}$ ) at end-

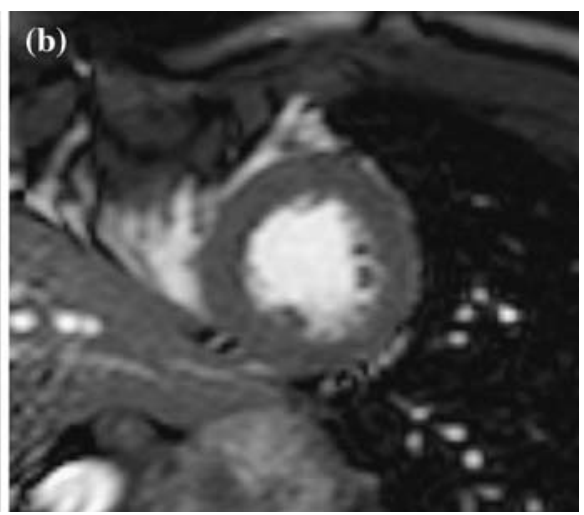

diastolic (a) and end-systolic (b) time points. Note the equal circular contraction of the left ventricular wall. Ejection fraction was $60 \%$ 


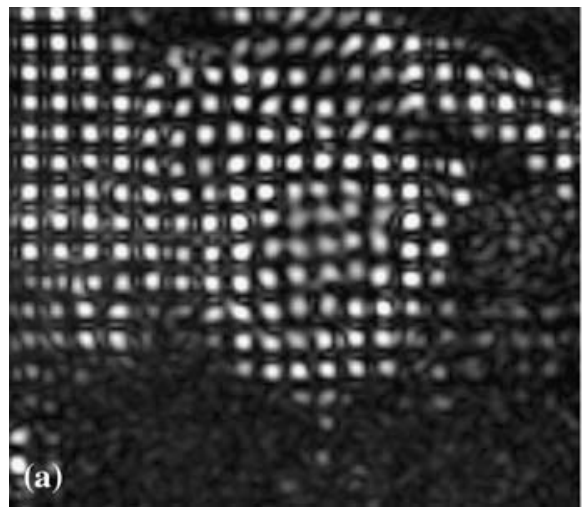

Fig. 8 Magnetic resonance imaging in a 22-years-old healthy male. Short-axis tagging imaging at left midventricular level with echo-planar imaging (EPI) tagging sequence with EPI factor 7, TR $30 \mathrm{~ms}$, TE $13 \mathrm{~ms}$, flip angle $20^{\circ}$, slice thickness

MRI tissue tagging by evaluating the grid-distortion throughout the cardiac cycle allows accurate analysis of diastolic strain and 3D cardiac motion (rotation, radial contraction, and translation) with high temporal resolution of about $40 \mathrm{~ms}$ [98]. Echocardiographic images do not allow this $3 \mathrm{D}$ reconstruction and quantification because of the absence of reference points within the myocardium, ultrasound beam parallel alignment difficulties with moving myocardium, and poor epicardial visualization [92]. On the other hand, the novel speckle tracking techniques might overcome this limitation [99].

\section{MRI of mitral regurgitation}

The mitral regurgitant fraction volume can be quantified with high accuracy by MRI, either directly by velocity mapping in the valvular plane (regurgitant fraction = forward/backward flow), or as a difference between LV stroke volume obtained by volumetric quantification and ejected volume in the proximal ascending aorta, assessed by velocity encoded MRI [100]. One-directional velocity-encoded MRI methods may lack accuracy, as the regurgitant jet may not be directed perpendicular to the imaged valvular plane. To overcome this problem, 3 directional blood flow vector velocity imaging has been developed, providing accurate and reproducible transvalvular mitral valve flow quantification [101] (Fig. 9).

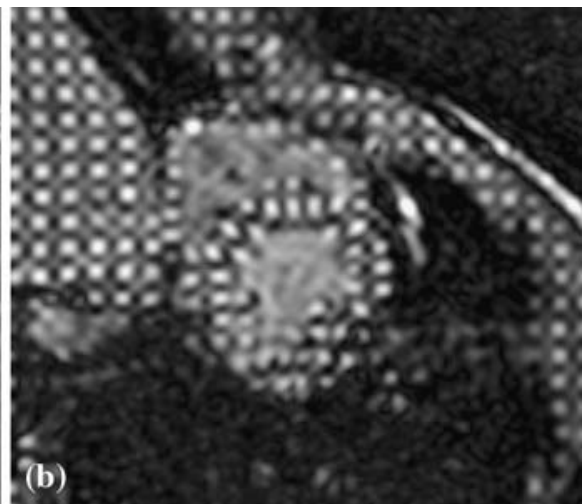

$8 \mathrm{~mm}$, at end-diastolic (a) and end-systolic (b) time points. Vector motion analysis of tagging points throughout the cardiac cycle allows left ventricular strain rate analysis
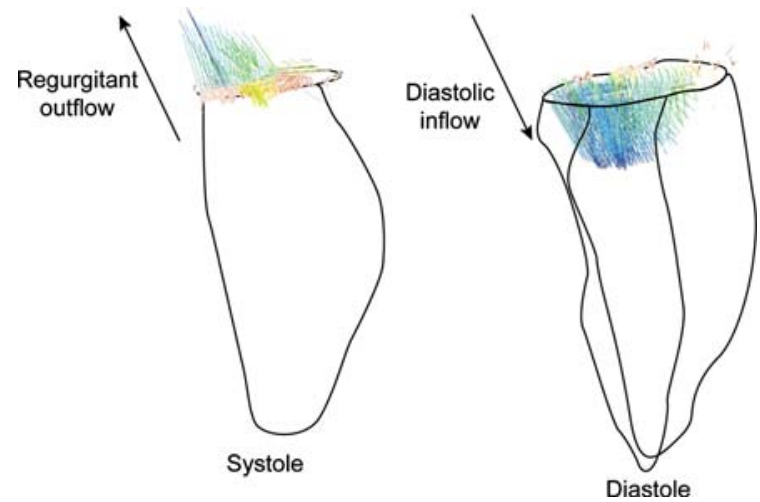

Fig. 9 Example of flow velocity reconstruction through the mitral valve plane from 3-directional velocity-encoded MRI. During systole, the regurgitant jet is clearly presented. During diastole, the inflow is visualized

MRI of left ventricular mechanical dyssynchrony

Presently, the method of choice for assessing LV mechanical dyssynchrony is TDI-echocardiography [102-105]. Several topics regarding the assessment of LV dyssynchrony remain unclear, such as the level of the ventricle where to assess dyssynchrony, and the number of ventricular wall segments requiring assessment. A compromise is necessary between optimal detection of mechanical delay and feasibility of examining numerous segments in clinical practice. Interrogation of only two segments may overlook a significant proportion of delayed myocardium, thus inadequately assessing dyssynchrony [33]. At yet 
there is no ideal echocardiographic mechanical dyssynchrony indicator, and this evaluation in patients with narrow QRS is currently not indicated. The echocardiographic parameters of dyssynchrony are not robust enough to withhold CRT, with proven morbidity and mortality [55]. A change of guidelines has already been proposed by some authors [5] while for others it is neither mandatory to alter current guidelines for patient selection nor essential to include echocardiographic assessment [55]. Most echocardiographic mechanical dyssynchrony analysis methods are based on longitudinal motion data [66]. However, cardiac contraction is mainly radial, and the longitudinal motion data in patients with HF may not provide the most accurate and comprehensive LV dyssynchrony data.

MRI has the potential to evaluate mechanical dyssynchrony either by tagging or velocity-encoded MRI [106]. Quantitative strain analysis based on 3D circumferential and longitudinal myocardial activation data has high spatial and temporal resolution, and has shown high reproducibility. Moreover, MRI data acquisition is largely operator and patient independent and may thus be better suited to characterize dyssynchronous HF and to identify appropriate candidates for CRT than Doppler echocardiographic methods. MRI myocardial tagging [96, 107, 108] can be used to calculate local myocardial motion or strain. Advances in the rapid analysis of tagged magnetic resonance images such as harmonic phase (HARP) and strain-encoded (SENC) imaging, and the design of novel global indexes of cardiac dyssynchrony may provide a more comprehensive method for selecting candidates for CRT. The HARP method measures the motion from tagged MR images by filtering certain regions in the frequency domain of the images called harmonic peaks [109, 110]. The HARP method measures the local strain of tissue by measuring the frequency of the tag lines. The number of tags per unit length is called the frequency of the tag pattern. If this tissue contracts, the tag lines become closer to each other and the tag frequency increases in proportion to the contraction, and vice versa. Circumferential strain in a given angular sector of each slice is then plotted during the cardiac cycle [106]. The new technique SENC imaging is derived from a standard myocardial tagging sequence that tags the tissue at end-diastole with a sinusoidal tag pattern designed to modulate the longitudinal magnetization orthogonal to the imaging plane. Deformations of tissue during systole will change the local frequency of the pattern in proportion to the through-plane strain component. The distribution of regional contraction (circumferential shortening in long-axis views or longitudinal compression in shortaxis views) is then displayed as contrast in the images. The SENC technique has several features that are well suited for assessing dyssynchronous HF and CRT, as it provides: (1) Instantaneous real-time quantitative strain measurements without the need for user intervention; (2) Higher spatial resolution over standard tagging as a result of reduced tag spacing; (3) Acquisition of both circumferential and longitudinal myocardial stain information; and (4) Assessment of regional function of both ventricles.

Velocity-encoded MRI, when applied for myocardial wall motion measurement $[111,112]$, potentially allows direct myocardial wall motion measurement similar to TDI (i.e., comparing velocity graphs obtained in different parts of the myocardial wall during systole). In a study where velocity-encoded MRI was compared to TDI, a strong correlation for LV dyssynchrony assessment was found between these two techniques. Moreover, agreement was excellent when patients were categorized according to severity of LV dyssynchrony (minimal, intermediate, or extensive): $95 \%$ of patients were equally classified with MRI and TDI [113]. These initial results show that MRI can provide similar information on LV dyssynchrony as TDI. Besides measuring longitudinal myocardial wall velocities (basal-toapex contraction and relaxation) in four-chamber orientation, MRI can also provide the longitudinal myocardial wall velocity acquired in short-axis orientation [114]. Dividing the circumference of the short axis into multiple segments and measuring the time of peak systolic velocity in each of these segments indicates the site of latest activation.

Finally, LV dyssynchrony can also be determined from wall thickening and wall thinning measurements in short-axis MRI (Fig. 10). The standard 16-segment model can be used. At short-axis imaging the basal level and mid-ventricular level are divided into six segments each. The apical level is divided into four segments. The endocardial and epicardial contours are determined in all phases [115]. For each of the 16 segments, the times to peak wall thickening and peak wall thinning are acquired. The means and standard 
Fig. 10 Example of LV dyssynchrony measurements in a healthy volunteer $(\mathbf{A}, \mathbf{B})$ and a patient with extensive dyssynchrony $(\mathbf{C}, \mathbf{D})$. In A and $\mathbf{C}$, the longitudinal velocities measured with MRI are presented. Sample volumes are placed in septal and lateral wall at the basal level. The mean velocities measured in these sample volumes are presented in $\mathbf{B}$ and $\mathbf{C}$. In $\mathbf{B}$, the peak systolic velocities of septal and lateral wall coincide. In D, a large delay between peak systolic velocities in septal and lateral wall of $115 \mathrm{~ms}$ is present
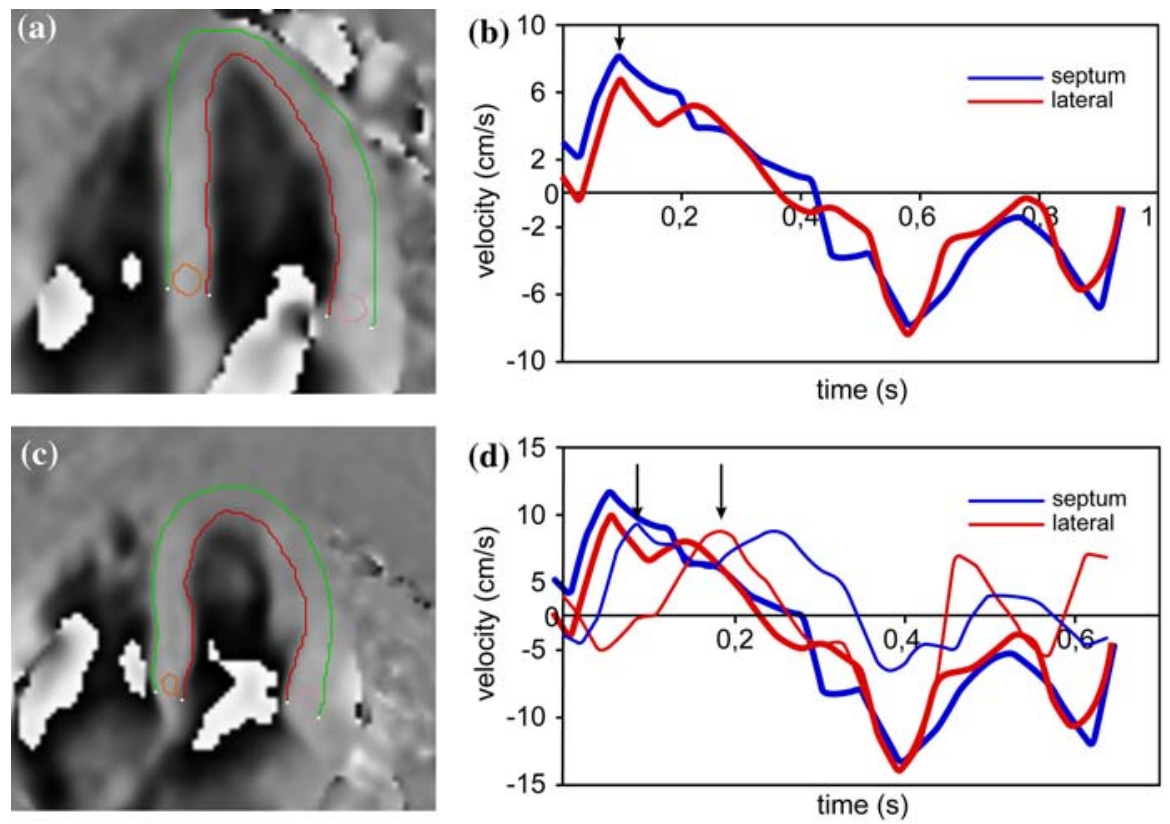

deviations are determined. A large standard deviation indicates a large spread in contraction patterns, thus more LV dyssynchrony.

\section{MRI of myocardial ischemia and viability}

Stress echocardiography and scintigraphic techniques are useful in clinical practice with wide availability for assessing ischemia, perfusion and viability. However, non-diagnostic echocardiography examinations are reported in 10-15\% of cases, mostly due to limited image quality and due to the fact that examinations are observer dependent [116]. Scintigraphic exams are sufficient reproducible but limitation in spatial resolution reduce sensitivity, while attenuation artefacts compromise specificity, whereas the radiation burden is also of concern [117]. MRI visualizes global and regional wall motion and systolic wall thickening with a high spatial and temporal resolution. Wall motion abnormalities can be detected at rest and high dose dobutamine stress with high rate of diagnostic accuracy, superior to that of dobutamine stress echocardiography. Cine loops of cardiac motion are acquired with steady state free precession gradient-echo techniques, where the imaging contrast is generated by the difference in magnetization between the blood and myocardium. MRI is especially beneficial in patients who have insufficient acoustic window [116]. First-pass perfusion MRI with excellent spatial and temporal resolution is currently the most accurate method for non-invasive assessment of myocardial perfusion [117].

Delayed contrast-enhanced MRI is extremely valuable for assessing viable and nonviable myocardium in infarcted and poorly contracting myocardial areas (Fig. 11).

Contrast-enhanced MRI enables depiction of transmural and non-transmural infarctions with better spatial and contrast resolution and better accuracy than scintigraphic techniques [118]. Combined assessment of scar tissue and LV dyssynchrony is needed to optimize prediction of response to CRT. It has been found that patients with transmural scar tissue in the posterolateral $\mathrm{LV}$ wall did not respond to CRT, even if extensive LV dyssynchrony existed. On the other hand, patients with non-transmural scar tissue in the same segments and with severe baseline LV dyssynchrony, showed excellent response (95\%) after CRT [119].

\section{Conclusion}

The well known efficacy of CRT, its high cost and significant percentage of non-responders justifies 


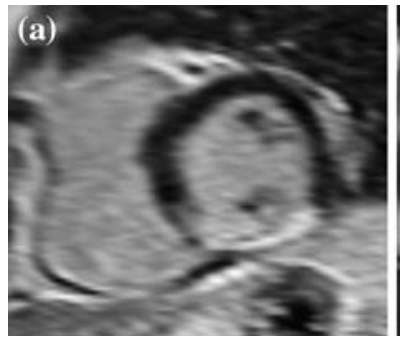

Fig. 11 Magnetic resonance imaging in a 65-years-old female who had a myocardial infarction in the past. Short-axis images at left midventricular level. Delayed enhancement technique (T1-weighted turbo-field echo sequence with turbo factor 40 and TR $3.9 \mathrm{~ms}$, TE $12 \mathrm{~ms}$, flip angle $15^{\circ}$, slice thickness $10 \mathrm{~mm}) 17 \mathrm{~min}$ following gadolinium-chelate administration showing delayed enhancement as sign of scar tissue in the

evaluation of the potential and applicability of the various imaging modalities for improved patient selection. Echocardiography has been the most frequently used technique and its potential has been fully explored. However, an ideal parameter representing mechanical dyssynchrony has not been recognised yet and there are some obstacles to the acquisition of data using echocardiography. As compared to echocardiography, cardiac MDCT and MRI are 3D techniques not limited by geometric assumptions, and less operator dependent. Use of cardiac MDCT can be mainly advantageous for noninvasively assessing the status of coronary arteries and veins and identifying whether or not patients have a suitable coronary vein for transvenous CRT LV lead placement. MDCT can also be used for determining LVEF and ventricular volumes either for CRT patient selection or follow-up CRT. The role for MDCT in assessing mechanical dyssynchrony, diastolic function, and mitral regurgitation seems limited due to the current limitation in temporal resolution and inability to measure flow directly.

Cardiac MRI has currently the greatest potential for improved assessment of patients who are candidates for CRT as it provides the unique capabilities to study many aspects of cardiac anatomy, ventricular and valvular regurgitant volumes, systolic and diastolic function, ischemia and viability in a single imaging session. Moreover, MRI has the potential to identify CRT responders by evaluating LV dyssynchrony and myocardial scarring, which can assist in the selection of the optimal CRT pacing site. After having decided, based on echocardiography or MRI, inferior wall regions (a). Functional imaging (balanced turbo field-echo sequence with TR $3.8 \mathrm{~ms}$, TE $1.9 \mathrm{~ms}$, flip angle $70^{\circ}$, slice thickness $8 \mathrm{~mm}$ ) at end-diastolic (b) and end-systolic (c) time points. Note the lack of wall thickening in the inferior wall regions that corresponds to the area of delayed enhancement. Ejection fraction was $36 \%$

that the patient is a potential candidate for CRT, MDCT may be used for depicting or excluding coronary artery disease and assessing the route for pacemaker lead implantation. Integrated imaging data provide a roadmap to the cardiologist to optimize the prediction of CRT response and potentially minimize inherent risks to the procedure.

Acknowledgements We gratefully acknowledge Sofia Cabral, MD, Severo Torres, MD and Lopes Gomes, MD, $\mathrm{PhD}$, from the Echocardiography Laboratory of the Santo António General Hospital - Oporto - Portugal, for providing the echocardiographic images used in this article.

\section{References}

1. Swedberg K, Cleland J, Dargie H et al (2005) Guidelines for diagnosis and treatment of chronic heart: executive summary (update 2005): The task force for diagnosis and treatment of chronic heart failure of European Society of Cardiology. Eur Heart J 26:1115-1140

2. Abraham WT, Fisher WG, Smith AL et al (2002) Cardiac resynchronization in chronic heart failure. N Engl J Med 346:1845-1853

3. Butter C, Auricchio A, Stellbrink C et al (2001) Effect of resynchronization therapy stimulation site on the systolic function of heart failure patients. Circulation 104:30263029

4. Macias A, Gavira JJ, Alegria E et al (2004) Effect of the left ventricular pacing site on echocardiographic parameters of ventricular dyssynchrony in patients receiving cardiac resynchronization therapy. Rev Esp Cardiol 57:138-145

5. Bax JJ, Abraham T, Barold SS et al (2005) Cardiac resynchronization therapy Part 1: issues before device implantation. J Am Coll Cardiol 46:2153-2167

6. Geleijns J, Kroft LJM, Bax JJ et al (2006) Techniques for cardiovascular computed tomography. In: Higgins CB, 
De Roos A (eds) MRI and CT of the cardiovascular system, 2nd edn. Lippincott Williams \& Wilkins, Philadelphia

7. Van der Geest RJ, Lelieveldt BPF, Reiber JHC (2006) Quantification in cardiac magnetic resonance imaging and computed tomography. In: Higgins CB, de Roos A (eds) MRI and CT of the cardiovascular system, 2nd edn. Lippincott Williams \& Wilkins, Philadelphia

8. Juergens KU, Fischbach R (2006) Left ventricular function studied with MDCT. Eur Radiol 16:342-357

9. Colucci WS, Braunwald E (2005) Patophysiology of Heart Failure. In: Zipes DP, Libby P, Brawnauld E (eds) Braunwald́s heart disease: a textbook of cardiovascular medicine, 7th edn. Elsevier Sanders, Philadelphia

10. Zei PC, Stevenson LW (2005) Epidemiology and prognosis of heart failure. In: Ellenbogen KA, Kay GN, WilKoff BL (eds) Device therapy for congestive heart failure, 1st edn. Elsevier Sanders, Philadelphia

11. Di Salvo TG, Mathier M, Semigran MJ et al (1995) Preserved right ventricular ejection fraction predicts exercise capacity and survival in advanced heart failure. J Am Coll Cardiol 5:1143-1153

12. Auricchio A, Stellbrink C, Block M et al (1999) Effect of pacing chamber and atrioventricular delay on acute systolic function of paced patients with congestive heart failure. Circulation 99:2993-3001

13. Kass DA, Chen CH, Curry C et al (1999) Improved left ventricular mechanics from acute VDD pacing in patients with dilated cardiomyopathy and ventricular conduction delay. Circulation 99:1567-1573

14. Nelson GS, Curry CW, Wyman BT et al (2000) Predictors of systolic augmentation from left ventricular preexcitation in patients with dilated cardiomyopathy and intraventricular conduction delay. Circulation 101: 2703-2709

15. Nelson GS, Berger RD, Fetics BJ et al (2000) Left ventricular or biventricular pacing improves cardiac function at diminished energy cost in patients with dilated cardiomyopathy and left bundle-branch block. Circulation 102:3053-3059

16. St John Sutton MG, Plappert T, Abraham WT et al (2003) Effect of cardiac resynchronization therapy on left ventricular size and function in chronic heart failure. Circulation 107:1985-1990

17. Yu CM, Chau E, Sanderson JE et al (2002) Tissue Doppler echocardiographic evidence of reverse remodeling and improved synchronicity by simultaneously delaying regional contraction after biventricular pacing therapy in heart failure. Circulation 105:438-445

18. Adams KF, Zannad F (1998) Clinical definition and epidemiology of advanced heart failure. Am Heart $\mathrm{J}$ 135:S204-S215

19. Nishimura RA, Tajik AJ (1997) Evaluation of diastolic filling of left ventricle in health and disease: Doppler echocardiography is the clinician's Rosetta stone. J Am Coll Cardiol 30:8-18

20. Mandinov L, Eberli FR, Seiler C et al (2000) Diastolic heart failure: a review. Cardiovascular Research 45: 813-825
21. Taylor RA (2005) Ventricular diastolic dysfunction. In: Roldan CA (ed) The ultimate echo guide, 1st edn. Lippincott \& Williams, Philadelphia

22. Bax JJ, Abraham T, Barold SS et al (2005) Cardiac resynchronization therapy Part 2: issues during and after device implantation and unsolved questions. J Am Coll Cardiol 46:2168-2182

23. St John Sutton MG, Plappert T, Hilpisch KE et al (2006) Sustained reverse left ventricular structural remodeling with cardiac resynchronization at one year is a function of etiology. Circulation 113:266-272

24. Carabello BA (2004) Ischemic mitral regurgitation and ventricular remodeling. J Am Coll Cardiol 43:384-385

25. Otsuji Y, Kumanohoso T, Yoshifuku S et al (2002) Isolated annular dilation does not usually cause important functional mitral regurgitation: comparison between patients with lone atrial fibrillation and those with idiopathic or ischemic cardiomyopathy. J Am Coll Cardiol 39:1651-1656

26. Yiu SF, Enriquez-Sarano M, Tribouilloy C et al (2000) Determinants of the degree of functional mitral regurgitation in patients with systolic left ventricular dysfunction: a quantitative clinical study. Circulation 102:14001406

27. Erlebacher JA, Barbarash S (2001) Intraventricular conduction delay and functional mitral regurgitation. Am J Cardiol 88:83-86

28. Brecker SJ, Xiao HB, Sparrow J et al (1992) Effects of dual-chamber pacing with short atrioventricular delay in dilated cardiomyopathy. Lancet 340:1308-1312

29. Bolling SF, Smolens IA, Pagani FD (2001) Surgical alternatives for heart failure. J Heart Lung Transplant 20:729-733

30. Kanzaki H, Bazaz R, Schwartzman D et al (2004) A mechanism for immediate reduction in mitral regurgitation after cardiac resynchronization therapy: insights from mechanical activation strain mapping. J Am Coll Cardiol 44:1619-1625

31. Stolen KQ, Kemppainen J, Ukkonen H et al (2003) Exercise training improves biventricular oxidative metabolism and left ventricular efficiency in patients with dilated cardiomyopathy. J Am Coll Cardiol 41: 460-467

32. Hawkins NM, Petrie MC, MacDonald MR et al (2006) Selecting patients for cardiac resynchronization therapy: electrical or mechanical dyssynchrony? Eur Heart J 27:1270-1281

33. Shenkman HJ, Pampati V, Khandelwal AK et al (2002) Congestive heart failure and QRS duration: establishing prognosis study. Chest 122:528-534

34. McCullough PA, Hassan SA, Pallekonda V et al (2005) Bundle branch block patterns, age, renal dysfunction, and heart failure mortality. Int J Cardiol 102:303-308

35. Silvet H, Amin J, Padmanabhan S et al (2001) Prognostic implications of increased QRS duration in patients with moderate and severe left ventricular systolic dysfunction. Am J Cardiol 88:182-185

36. Auricchio A, Yu CM (2004) Beyond the measurement of QRS complex toward mechanical dyssynchrony: cardiac 
resynchronisation therapy in heart failure patients with a normal QRS duration. Heart 90:479-481

37. Yu CM, Yang H, Lau CP et al (2003) Regional left ventricle mechanical asynchrony in patients with heart disease and normal QRS duration: implication for biventricular pacing therapy. Pacing Clin Electrophysiol 26:562-570

38. Lecoq G, Leclercq C, Leray E et al (2005) Clinical and electrocardiographic predictors of a positive response to cardiac resynchronization therapy in advanced heart failure. Eur Heart J 26:1094-1100

39. Pitzalis MV, Iacoviello M, Romito R et al (2005) Ventricular asynchrony predicts a better outcome in patients with chronic heart failure receiving cardiac resynchronization therapy. J Am Coll Cardiol 45:65-69

40. Bax JJ, Bleeker GB, Marwick TH et al (2004) Left ventricular dyssynchrony predicts response and prognosis after cardiac resynchronization therapy. J Am Coll Cardiol 44:1834-1840

41. Alonso C, Leclercq C, Victor F et al (1999) Electrocardiographic predictive factors of long-term clinical improvement with multisite biventricular pacing in advanced heart failure. Am J Cardiol 84:1417-1421

42. Blanc JJ, Etienne Y, Gilard M et al (1997) Evaluation of different ventricular pacing sites in patients with severe heart failure: results of an acute hemodynamic study. Circulation 96:3273-3277

43. Kass DA, Chen CH, Curry C et al (1999) Improved left ventricular mechanics from acute VDD pacing in patients with dilated cardiomyopathy and ventricular conduction delay. Circulation 99:1567-1573

44. Turner MS, Bleasdale RA, Mumford CE et al (2004) Left ventricular pacing improves haemodynamic variables in patients with heart failure with a normal QRS duration. Heart 90:502-505

45. Leclercq C, Faris O, Tunin R et al (2002) Systolic improvement and mechanical resynchronization does not require electrical synchrony in the dilated failing heart with left bundle-branch block. Circulation 106:17601763

46. Gheorghiade M, Bonow RO (1998) Chronic heart failure in the United States: a manifestation of coronary artery disease. Circulation 97:282-289

47. Abraham WT, Hayes DL (2003) Cardiac resynchronization therapy for heart failure. Circulation 108:2596-2603

48. Puglisi A, Lunati M, Marullo AG et al (2004) Limited thoracotomy as a second choice alternative to transvenous implant for cardiac resynchronisation therapy delivery. Eur Heart J 25:1063-1069

49. Singh JP, Houser S, Heist EK et al (2005) The coronary venous anatomy: a segmental approach to aid cardiac resynchronization therapy. J Am Coll Cardiol 46:68-74

50. Ansalone G, Giannantoni P, Ricci R et al (2002) Doppler myocardial imaging to evaluate the effectiveness of pacing sites in patients receiving biventricular pacing. J Am Coll Cardiol 39:489-499

51. Shiller NB, Shah PM, Crawford M et al (1989) Recommendation for quantification of the left ventricule by twodimensional echocardiography. American Society of Echocardiography Committee on Standards, Subcommitee on Quantification of Two-dimensional Echocardiograms. J Am Soc Echocardiogr 2:358-367

52. Zoghbi WA, Plana JC (2005) Ventricular systolic dysfunction. In: Roldan CA (ed) The ultimate echo guide, 1st edn. Lippincott \& Williams, Philadelphia

53. Ashley PA, Roldan CA (2005) Mitral Regurgitation. In: Roldan CA (ed) The ultimate echo guide, 1st edn. Lippincott \& Williams, Philadelphia

54. Cazeau S, Bordachar P, Jauvert G et al (2003) Echocardiographic modelling of cardiac dyssynchrony before and during multisite stimulation: a prospective study. Pacing Clin Electrophysiol 26:137-143

55. Bader H, Garrigue S, Lafitte S et al (2004) Intra-left ventricular electromechanical asynchrony: a new independent predictor of severe cardiac events in heart failure patients. J Am Coll Cardiol 43:248-256

56. Ghio S, Constantin C, Klersy C et al (2004) Interventricular and intraventricular dyssynchrony are common in heart failure patients, regardless of QRS duration. Eur Heart J 25:571-578

57. Cleland JG, Daubert JC, Erdmann E et al (2001) The CARE-HF study (CArdiac REsynchronisation in Heart Failure study): rationale, design and end-points. Eur J Heart Fail 3:481-489

58. Yu CM, Abraham WT, Bax JJ et al (2005) Predictors of response to cardiac resynchronization therapy (PROSPECT) - study design. Am Heart J 149:600-605

59. Pitzalis MV, Iacoviello M, Romito R et al (2002) Cardiac resynchronization therapy tailored by echocardiographic evaluation of ventricular asynchrony. J Am Coll Cardiol 40:1615-1622

60. Marcus GM, Rose E, Viloria EM et al (2005) Septal to posterior wall motion delay fails to predict reverse remodelling or clinical improvement in patients undergoing cardiac resynchronization therapy. J Am Coll Cardiol 46:2208-2214

61. D'hooge J, Heimdal A, Jamal F et al (2000) Regional strain and strain rate measurements by cardiac ultrasound: principles, implementation and limitations. Eur J Echocardiogr 1:154-170

62. Pislaru C, Abraham TP, Belohlavek M (2002) Strain and strain rate echocardiography. Curr Opin Cardiol 17:443454

63. Popovic ZB, Grimm RA, Perlic G et al (2002) Noninvasive assessment of cardiac resynchronization therapy for congestive heart failure using myocardial strain and left ventricular peak power as parameters of myocardial synchrony and function. J Cardiovasc Electrophysiol 13:1203-1208

64. Yu CM, Fung JW, Zhang Q et al (2004) Tissue Doppler imaging is superior to strain rate imaging and postsystolic shortening on the prediction of reverse remodelling in both ischemic and nonischemic heart failure after cardiac resynchronization therapy. Circulation 110:66-73

65. Sogaard P, Egeblad H, Kim Y et al (2002) Tissue Doppler imaging predicts improved systolic performance and reversed left ventricular remodelling during long-term cardiac resynchronization therapy. J Am Coll Cardiol 40:723-730 
66. Murphy RT, Sigurdsson G, Mulamalla S et al (2006) Tissue synchronization imaging and optimal left ventricular pacing site in cardiac resynchronization therapy. Am J Cardiol 97:1615-1621

67. Krenning BJ, Szili-Torok T, Voormolen MM et al (2004) Guiding and optimization of resynchronization therapy with dynamic three-dimensional echocardiography and segmental volume-time curves: a feasibility study. Eur Heart Fail 6:619-625

68. Kapetanakis S, CooKlin M, Monaghan MJ (2004) Mechanical resynchronization in biventricular pacing illustrated by real time transthoracic three dimensional echocardiography. Heart 90:482

69. Mollet NR, Cademartiri F, Van Mieghem CA et al (2005) High-resolution spiral computed tomography coronary angiography in patients referred for diagnostic conventional coronary angiography. Circulation 112:2318-2323

70. Leber AW, Knez A, Von Ziegler F et al (2005) Quantification of obstructive and nonobstructive coronary lesions by 64-slice computed tomography: a comparative study with quantitative coronary angiography and intravascular ultrasound. J Am Coll Cardiol 46:147-154

71. Nicolaou K, Knetz A, Rist C et al (2006) Accuracy of 64MDCT in the diagnosis of ischemic heart disease. AJR Am J Roentgenol 187:111-117

72. Raff GL, Gallagher MJ, O’Neill WW et al (2005) Diagnostic accuracy of noninvasive coronary angiography using 64-slice spiral computed tomography. J Am Coll Cardiol 46:552-557

73. Raman SV, Shah M, McCarthy B et al (2006) Multidetector row cardiac computed tomography accurately quantifies right and left ventricular size and function compared with cardiac magnetic resonance. Am Heart J 151:736-744

74. Dogan H, Kroft LJ, Bax JJ et al (2006) MDCT assessment of right ventricular systolic function. AJR Am J Roengenol 186(6 suppl 2): S366-S370

75. Belge B, Coche E, Pasquet A et al (2006) Accurate estimation of global and regional cardiac function by retrospectively gated multidetector row computed tomography: comparison with cine magnetic resonance imaging. Eur Radiol 16:1424-1433

76. Schuijf JD, Bax JJ, Shaw LJ et al (2006) Meta-analysis of comparative diagnostic performance of magnetic resonance imaging and multislice computed tomography for non-invasive coronary angiography. Am Heart $\mathrm{J}$ 151:404-411

77. Baks T, Cademartiri F, Moelker AD et al (2006) Multislice computed tomography and magnetic resonance imaging for the assessment of reperfused acute myocardial infarction. J Am Coll Cardiol 48:144-152

78. Mahnken AH, Koos R, Katoh M et al (2005) Assessment of myocardial viability in reperfused acute myocardial infarction using 16-slice computed tomography in comparison with magnetic resonance imaging. J Am Coll Cardiol 45:2042-2047

79. Jongbloed MR, Lamb HJ, Bax JJ et al (2005) Noninvasive visualization of the cardiac venous system using multislice computed tomography. J Am Coll Cardiol 45:749-753
80. Abraham WT, Hayes DL (2003) Cardiac resynchronization therapy for heart failure. Circulation 108:2596-2603

81. Vander Salm TJ (1993) Coronary sinus cannulation: a technique to overcome an obstructing thebesian valve. Ann Thorac Surg 56:1441-1442

82. Von Ludinghausen M (2003) The venous drainage of the human myocardium. Adv Anat Embryol Cell Biol 168(Suppl I):I104

83. Corcoran SJ, Lawrence C, McGuire MA (1999) The valve of Vieussens: an important cause of difficulty in advancing catheters into the cardiac veins. J Cardiovasc Electrophysiol 10:804-808

84. Nagel E (2004) Indications for cardiovascular magnetic resonance imaging. In: Nagel E, Van Rossum AC, Fleck E (eds) Cardiovascular magnetic resonance, 1st edn. Steinkoff Darmstadt, Würzburg

85. DymarkowsKi S, Hamaekers P (2005) Practical Setup. In: Bogoaert J, DymarkowsKi S, Taylor AM (eds) Clinical cardiac MRI, 2nd edn. Springer, Berlin

86. Roguin A, Zviman MM, Meininger GR et al (2004) Modern pacemaker and implantable cardioverter/defibrillator systems can be magnetic resonance imaging safe: in vitro and in vivo assessment of safety and function at $1.5 \mathrm{~T}$. Circulation 110:475-482

87. Shellock FG, Fieno DS, Thomson LJ et al (2006) Cardiac pacemaker: in vitro assessment at $1.5 \mathrm{~T}$. Am Heart J 151:436-443

88. Lamb HJ, Kozerke S, Doornbos J et al. (2006) Clinical approach to cardiovascular magnetic resonance technique. In: Higgins CB, De Roos A (eds) MRI and CT of the cardiovascular system, 2nd edn. Lippincott Williams \& Wilkins, Philadelphia

89. Rademakers FE (2004) Left ventricular myocardial tagging. In: Nagel E, Van Rossum AC, Fleck E (eds) Cardiovascular magnetic resonance, 1st edn. Steinkoff Darmstadt, Würzburg

90. Paelinck BP, Lamb HJ, Bax JJ et al (2002) Assessment of diastolic function by cardiovascular magnetic resonance. Am Heart J 144:198-205

91. Hartiala JJ, Mostbeck GH, Foster E et al (1993) Velocityencoded cine MRI in the evaluation of left ventricular diastolic function. Measurement of mitral valve and pulmonary vein flow velocities and flow volume across the mitral valve. Am Heart J 125:1054-1066

92. Mohiaddin RH, Gatehouse PD, Henien M et al (1997) Cine MR Fourier velocimetry of blood flow through cardiac valves: comparison with Doppler echocardiography. J Magn Reson Imaging 7:657-663

93. Kayser HM, Stoel BC, Van der Wall EE et al (1997) MR velocity mapping of tricuspid flow: correction for through-plane motion. J Magn Reson Imaging 7:669673

94. Kasprzak JD, Paelinck B, Ten Cate FJ et al (1999) Comparison of native and contrast-enhanced harmonic echocardiography for visualization of left ventricular endocardial border. Am J Cardiol 83:211-217

95. Fyrenius A, Wigstrom L, Bolger AF et al (1999) Pitfalls in Doppler evaluation of diastolic function: insights from 3-dimensional magnetic resonance imaging. J Am Soc Echocardiogr 12:817-826 
96. Wedeen VJ (1992) Magnetic resonance imaging of myocardial kinematics: technique to detect, localize, and quantify the strain rates of the active human myocardium. Magn Reson Med 27:52-67

97. Paelinck BP, De Roos A, Bax JJ et al (2005) Feasibility of tissue magnetic resonance imaging: a pilot study in comparison with tissue Doppler imaging and invasive measurement. J Am Coll Cardiol 45:1109-1116

98. Fischer SE, McKinnon GC, Scheidegger MB et al (1994) True myocardial motion tracking. Magn Reson Med 31:401-413

99. Suffoletto MS, Dohi K, Cannesson M et al (2006) Novel speckle-tracking radial strain from routine black-andwhite echocardiographic images to quantify dyssynchrony and predict response to cardiac resynchronization therapy. Circulation 113:960-968

100. Arheden H, Ståohlberg (2006) Blood flow measurements. In: Higgins CB, De Roos A (eds) MRI and CT of the cardiovascular system, 2nd edn. Lippincott Williams \& Wilkins, Philadelphia

101. Westenberg JJ, Danilouchkine MG, Doornbos J et al (2004) Accurate and reproducible mitral valvular blood flow measurement with three-directional velocity-encoded magnetic resonance imaging. J Cardiovasc Magn Reson 6: 767-776

102. Yu CM, Chau E, Sanderson JE et al (2002) Tissue Doppler echocardiographic evidence of reverse remodeling and improved synchronicity by simultaneously delaying regional contraction after biventricular pacing therapy in heart failure. Circulation 105:438-445

103. Sogaard P, Egeblad H, Kim Y et al (2002) Tissue Doppler imaging predicts improved systolic performance and reversed left ventricular remodelling during long-term cardiac resynchronization therapy. J Am Coll Cardiol 40:723-730

104. Bax JJ, Molhoek SG, Van Erven L et al (2003) Usefulness of myocardial tissue Doppler echocardiography to evaluate left ventricular dyssynchrony before and after biventricular pacing in patients with idiopathic dilated cardiomyopathy. Am J Cardiol 91:94-97

105. Bleeker GB, Schalij MJ, Molhoek SG et al (2005) Comparison of effectiveness of cardiac resynchronization therapy in patients $<70$ versus $\geq 70$ years of age. Am J Cardiol 96:420-422

106. Lardo AC, Abraham TP, Kass DA (2005) Magnetic resonance imaging assessment of ventricular dyssynchrony: current and emerging concepts. J Am Coll Cardiol 46:2223-2228
107. Axel L, Dougherty L (1989) MR imaging of motion with spatial modulation of magnetization. Radiology 171:841-845

108. Osman NF, Prince JL (2000) Visualizing myocardial function using HARP MRI. Phys Med Biol 45:1665-1682

109. Osman NF, McVeigh ER, Prince JL (2000) Imaging heart motion using harmonic phase MRI. IEEE Trans Med Imaging 19:186-202

110. Zerhouni EA, Parish DM, Rogers WJ et al (1988) Human heart: tagging with MR imaging: a method for noninvasive assessment of myocardial motion. Radiology 169:59-63

111. Prinzen FW, Hunter WC, Wyman BT et al (1999) Mapping of regional myocardial strain and work during ventricular pacing: experimental study using magnetic resonance imaging tagging. J Am Coll Cardiol 33: 1735-1742

112. Leclercq C, Faris O, Tunin R et al (2002) Systolic improvement and mechanical resynchronization does not require electrical synchrony in the dilated failing heart with left bundle-branch block. Circulation 106:1760-1763

113. Westenberg JJ, Lamb HJ, Van der Geest RJ et al (2006) Assessment of left ventricular dyssynchrony in patients with conduction delay and idiopathic dilated cardiomyopathy head-to-head comparison between tissue Doppler imaging and velocity-encoded magnetic resonance imaging. J Am Coll Cardiol 47:2042-2048

114. Markl M, Schneider B, Hennig J (2002) Fast phase contrast cardiac magnetic resonance imaging: improved assessment and analysis of left ventricular wall motion. J Magn Reson Imaging 15:642-653

115. Van der Geest RJ, Reiber JHC (1999) Quantification in cardiac MRI. J Magn Reson Imaging 10:602-608

116. Nagel E (2006) Left ventricular function in ischemic heart disese. In: Higgins CB, De Roos A (eds) MRI and CT of the cardiovascular system, 2nd edn. Lippincott Williams \& Wilkins, Philadelphia

117. Schwitter J (2006) Myocardial perfusion in ischemic heart disease. In: Higgins CB, De Roos A (eds) MRI and CT of the cardiovascular system, 2nd edn. Lippincott Williams \& Wilkins, Philadelphia

118. Kim RJ, Fieno DS, Parrish TB et al (1999) Relationship of MRI delayed contrast enhancement to irreversible injury, infarct age, and contractile function. Circulation 100:1992-2002

119. Bleeker GB, Kaandorp TM, Lamb HJ et al (2006) Effect of posterolateral scar tissue on clinical and echocardiographic improvement after cardiac resynchronization therapy. Circulation 113:969-976 